EDITORIAL

\title{
Myocardial metabolic manipulation: a new therapeutic approach in heart failure?
}

\author{
E O'Meara, J J V McMurray
}

\section{Myocardial metabolic manipulation using drugs such as trimetazidine may offer a new therapeutic approach to the treatment of heart failure}

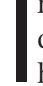
n most "developed" countries, coronary artery disease is now the most common cause of heart failure due to reduced left ventricular systolic function. Much, however, still needs to be understood about the relation between these two conditions. Myocardial infarction is a definite cause of ventricular damage and heart failure. Whether heart failure commonly occurs in patients with coronary artery disease, but without prior infarction, is much less clear. Similarly, there is not a consensus about the goals behind the treatment of coronary artery disease in patients with heart failure. Relief of angina is an obvious aim. Improving prognosis is another, though how this is achieved is less obvious, especially in patients without angina. There has also been much interest in the notion that, in these patients, ameliorating one or more of the various manifestations of myocardial ischaemia, assuming that they can be accurately measured, might improve ventricular function and thereby the symptoms of heart failure and prognosis.

There are many potential approaches to the treatment of myocardial ischaemia in patients with coronary artery disease, reduced left ventricular systolic function, and heart failure. Percutaneous or surgical "revascularisation" is indicated for relief of angina but may be risky. The value of "revascularisation" in patients without angina is unknown and two studies are currently underway to determine whether these interventions might improve prognosis. ${ }^{12}$

Numerous conventional anti-ischaemic drug treatments are also available. One type, a $\beta$ blocker, improves left ventricular function, the symptoms of heart failure, and clinical outcomes, but also has these benefits in patients with heart failure and no coronary disease. Others, such as nitrates, reduce ischaemia but do not improve systolic function or heart failure. There are also anti-ischaemic drugs which have detrimental effects in patients with heart failure, notably the calcium channel blockers, with the exception of amlodipine and, perhaps, felodipine. Lastly, some drugs, such as angiotensin converting enzyme (ACE) inhibitors and statins, have an anti-infarction effect (presumably protecting from further ventricular injury and failure), but do not relieve ischaemia.
See end of article for
authors' affiliations
$\ldots \ldots \ldots . . . . . . . . . . . . .$.
Correspondence to:
Professor John J V
McMurray, Department of
Cardiology, Western
Infirmary, Glasgow, G11
6NT, UK; i.mcmurray@
bio.gla.ac.uk
.........................

See end of article for
authors' affiliations
$\ldots \ldots \ldots . . . . . . . . . . . . .$.
Correspondence to:
Professor John J V
McMurray, Department of
Cardiology, Western
Infirmary, Glasgow, G11
6NT, UK; i.mcmurray@
bio.gla.ac.uk
.........................
Heart 2005;91:131-132. doi: 10.1136/hrt.2004.041756

\section{MYOCARDIAL METABOLIC MANIPULATION}

For many years there has also been interest in another approach to treating myocardial ischaemia in patients with heart failure. This approach involves metabolic manipulation of the myocardium. ${ }^{3}$ At least four agents may act in this way: etomoxir, perhexiline, ranolazine, and trimetazidine. ${ }^{3}$ None of these drugs is believed to have a significant inotropic, chronotropic, or vasodilator action at rest or during exercise, a very attractive feature for patients already taking multiple vasoactive medications.

What is the hypothesis behind myocardial metabolic manipulation? Under aerobic conditions, the human heart mainly uses free fatty acids (FFA) to generate energy $(60-90 \%$ of the energy produced), with carbohydrate metabolism contributing only a small proportion (10$40 \%$ ) of the adenosine triphosphate (ATP) generated. However, under hypoxic conditions-for example, during ischaemia-a shift towards glucose metabolism is desirable; although FFA metabolism yields more ATP per gram of substrate, it requires greater oxygen consumption. During ischaemia, FFA metabolism suppresses glucose oxidation, increases lactate and hydrogen ion production and, thus, leads to a fall in intracellular $\mathrm{pH}^{3}$ This accelerates myocyte sodium and calcium overload, exacerbating the ischaemic insult and cardiac dysfunction. Moreover, ATP itself is also necessary to maintain cellular ionic homeostasis. Although glucose metabolism is increased during ischaemia, FFA metabolism is still predominant. Pharmacological interventions aimed at reducing FFA oxidation and increasing glucose metabolism may, therefore, be "cytoprotective" in myocardium subjected to repeated ischaemia. Similarly, there is also evidence that enhancement of carbohydrate oxidation in heart failure (as opposed to demand ischaemia) increases cardiac contractility and that reliance on FFA oxidation in heart failure may contribute to systolic dysfunction; put simply, the heart seems to pump more efficiently if the fuel is glucose. In other words, a shift from FFA oxidation to glucose oxidation may be good for both ischaemia and myocardial systolic dysfunction.

\section{TRIMETAZIDINE}

Trimetazidine is one of a number of drugs which may act in this way. Its molecular target,

Abbreviations: $A C E$, angiotensin converting enzyme; ATP, adenosine triphosphate; FFT, free fatty acids; NYHA, New York Heart Association 
although still debated, is thought to be the last enzyme involved in mitochondrial fatty acid B-oxidation, long chain 3-ketoacyl coenzyme A thiolase. ${ }^{4}$ Whatever the precise molecular mechanism, the anti-ischaemic effect of trimetazidine is likely due to a metabolic shift, leading to increased glucose oxidation.

In this issue of Heart, Di Napoli and colleagues report an open label, single centre study examining the effect of trimetazidine in patients who, after angiography, were deemed not to be candidates for "revascularisation". ${ }^{5}$ We are not told, however, what proportion of patients had angina or what other evidence there was of ischaemia. Though most patients were treated with an inhibitor of the reninangiotensin system, only about half were taking a $\beta$ blocker. Treatment with trimetazidine, for 18 months, was associated with improvements in New York Heart Association (NYHA) functional class, left ventricular ejection fraction, and other indices of cardiac remodelling. In addition, plasma $\mathrm{C}$ reactive protein concentration increased over time in the control group but remained stable in the trimetazidine group.

What are we to make of these findings? The changes in remodelling are easiest to interpret as the echocardiographic analyses were blinded; however, the open label study design makes the assessment of NYHA class much less reliable. The study was also too small to give reliable information on safety. The effects of trimetazidine on remodelling are of particular interest because it seems increasingly clear that drugs that increase ejection fraction and reduce ventricular volumes are likely to improve symptoms and prognosis in heart failure, in the absence of any other harmful, offsetting action. Consequently, the findings of Di Napoli and colleagues are potentially very important. Clearly, however, more information is needed. In precisely what type of patient are these effects obtained? Is it only in patients with angina, or only where there is demonstrable myocardial ischaemia, or is trimetazidine beneficial in all patients with coronary artery disease? This type of treatment may have a particular role in diabetics. ${ }^{67}$ Is there benefit in more advanced heart failure as these patients already demonstrate a switch from FFA to glucose oxidation ${ }^{8}$ Are the effects on remodelling incremental to best available current treatment-that is, an ACE inhibitor, $\beta$ blocker, and angiotensin receptor blocker, aldosterone blocker, or both? Testing the effect of trimetazidine in addition to a $\beta$ blocker is especially important as it has been postulated that these drugs may also induce a metabolic shift, although the evidence is not strong. ${ }^{9}$

If the findings of Di Napoli and colleagues can be replicated and extended (and if there are no safety concerns), there would be a strong case for an outcome trial with trimetazidine (or a similar agent ${ }^{10}$ ) in patients with heart failure and coronary artery disease.

\section{Authors' affiliations}

E O'Meara, J J V McMurray, Department of Cardiology, Western Infirmary, Glasgow, UK

\section{REFERENCES}

1 Jones RH. Is it time for a randomized trial of surgical treatment of ischemic heart failure? J Am Coll Cardiol 2001;37:1210-3.

2 Cleland JG, Freemantle N, Ball SG, et al. The heart failure revascularisation trial (HEART): rationale, design and methodology. Eur J Heart Fail 2003; 5:295-303.

3 Lee L, Horowitz J, Frenneaux M. Metabolic manipulation in ischaemic heart disease, a novel approach to treatment. Eur Heart J 2004;25:634-41.

4 Kantor PF, Lucien A, Kozak R, et al. The antianginal drug trimetazidine shifts cardiac energy metabolism from fatty acid oxidation to glucose oxidation by inhibiting mitochondrial long-chain 3-ketoacyl coenzyme A thiolase. Circ Res 2000;86:580-8.

5 Di Napoli P, Taccardi AA, Barsotti A. Long term cardioprotective action of trimetazidine and potential effect on the inflammatory process in patients with ischaemic dilated cardiomyopathy. Heart 2005;91:161-5.
6 Rosano GM Vitale $C$, Sposato $B$, et al. Trimetazidine improves left ventricular function in diabetic patients with coronary artery disease: a double-blind placebo-controlled study. Cardiovasc Diabetol 2003;2:16.

7 Thrainsdottir IS, von Bibra H, Malmberg K, et al. Effects of trimetazidine on left ventricular function in patients with type 2 diabetes and heart failure. J Cardiovasc Pharmacol 2004;44:101-8.

8 Sack MN, Rader TA, Park S, et al. Fatty acid oxidation enzyme gene expression is downregulated in the failing heart. Circulation 1996:94:2837-42.

9 Wallhaus TR, Taylor M, DeGrado TR, et al. Myocardial free fatty acid and glucose use after carvedilol treatment in patients with congestive heart failure. Circulation 2001;103:2441-6.

10 Chaitman BR, Pepine CJ, Parker JO, et al. for the Combination Assessment of Ranolazine In Stable Angina (CARISA) Investigators. Effects of ranolazine with atenolol, amlodipine, or diltiazem on exercise tolerance and angina frequency in patients with severe chronic angina. JAMA 2004;291:309-16.

\section{WEB TOP 10}

www.heartjnl.com

These articles scored the most hits on Heart's website during November 2004

1 Should all patients with an acute myocardial infarction be referred for direct PTCA?

PP de Jaegere, PW Serruys, ML Simoons

November 2004;90:1352-7. (Education in Heart)

2. Theory and practice of defibrillation: (1) Atrial fibrillation and DC conversion

AAJ Adgey, SJ Walsh

December 2004;90:1493-8. (Education in Heart)

3 Warfarin for non-rheumatic atrial fibrillation: five year experience in a district general hospital

ZR Yousef, SC Tandy, V Tudor, F Jishi, RJ Trent, DK Watson, RPW Cowell

November 2004;90:1259-62. (Cardiovascular medicine)

4 Management of hypertension before, during, and after pregnancy

PR James, C Nelson-Piercy

December 2004;90:1499-504. (Education in Heart)

5 Joint British recommendations on prevention of coronary heart disease in clinical practice

December 1998;80:1-29.

6 Pathologic assessment of the vulnerable human coronary plaque

FD Kolodgie, $R$ Virmani, AP Burke, A Farb, DK Weber, $R$ Kutys, AV Finn, HK Gold

December 2004;90:1385-91. (Mini-symposium)

7 Management of acute coronary syndromes: an update KAA Fox

June 2004;90:698-706. (Education in Heart)

8 Biochemical markers of myocyte injury in heart failure

Y Sato, T Kita, Y Takatsu, T Kimura

October 2004;90:1110-3. (Review)

9 Plaque stabilisation in coronary artery disease: introduction

B Meier

December 2004;90:1384. (Mini-symposium)

10 Tissue Doppler, strain, and strain rate echocardiography for the assessment of left and right systolic ventricular function

$D$ Pellerin, $R$ Sharma, P Elliott, C Veyrat

November 2003;89(suppl III):iii9-17. (Supplement)

Visit the Heart website for hyperlinks to these articles, by clicking on "Top 10 papers"

www.heartinl.com 